\title{
MINAS Y MINEROS: PRESENCIA DE METALES EN SEDIMENTOS Y RESTOS HUMANOS AL SUR DE LA SIERRA GORDA DE QUERÉTARO EN MÉXICO*
}

\author{
MINES AND MINERS: METALS IN SEDIMENTS AND HUMAN REMAINS \\ FROM SOUTHERN SIERRA GORDA, QUERÉTARO, MEXICO
}

\author{
Elizabeth Mejía Pérez Campos ${ }^{1}$ y Alberto Juan Herrera Muñoz ${ }^{1}$
}

\begin{abstract}
La arqueología de la Sierra Gorda posee un encanto especial y es un reto académico. Se trata de la primera región en México donde la minería prehistórica subterránea de cinabrio fue registrada en tiempos modernos. El estudio de la sociedad antigua con una economía especializada orientada a la minería del cinabrio en época prehispánica nos condujo a preguntarnos cómo es que los habitantes antiguos reconocieron, se apropiaron y usaron este paisaje. En consecuencia, cómo se distribuyeron los asentamientos y las minas antiguas al sur de la Sierra Gorda. En nuestro tiempo, sabemos que el mercurio metálico, el sulfuro de mercurio y otros compuestos relacionados con el $\mathrm{Hg}$ son peligrosos para el medio ambiente y pueden ser persistentes en el tiempo. En consecuencia, nos preguntamos: ¿De qué manera esta especialización económica afectó el ambiente y a sus habitantes, tanto en el pasado como en tiempos modernos?

Palabras claves: Sierra Gorda, arqueología, patrón de asentamiento, Toluquilla, Las Ranas, cinabrio, Hg, minería prehistórica.
\end{abstract}

Sierra Gorda's archaeology has a special charm and it is and academic challenge. This is the first region in Mexico where prehistoric underground mining was practiced in modern times. The study in this region of an ancient society, with a specialized economy oriented to cinnabar mining during prehispanic times, leads us to ask how the ancient people recognized the landscape and how they appropriated and used it. ¿How did the Sierra Gorda inhabitants distribute their settlements and mines within their territory? Today we know that metallic mercury, mercury sulfides and other compounds linked to Hg are dangerous for the environment and can be persistent through time. Thus, we consider how economic specialization affected the environment and settlers in both the past and present time in Sierra Gorda.

Key words: Sierra Gorda, Archaeology, Settlement pattern, Toluquilla, Las Ranas, cinnabar, Hg, prehistoric mining.

El cinabrio fue ampliamente utilizado desde la prehistoria en diferentes lugares del mundo, tales como Ydria en la ex Yugoslavia, Essex en Inglaterra, Dordoña en Francia, Chavín de Huantar en Perú (Forbes 1965-67; Shepherd 1980), Japón (Minami 2005) y España (Domínguez-Bella 2010, 2011; Martín-Gil et al. 1994).

La Sierra Gorda en México también contiene importantes yacimientos de cinabrio que fueron conocidos y explotados en época prehispánica. De ello existen evidencias reportadas desde 1970 por el ingeniero Adolphus Langenscheidt, al realizar un rescate de restos arqueológicos y hallar restos óseos, vasijas, instrumental lítico, restos de animales y vegetales que fechó hacia el 15 d.C. (Langenscheidt 1970).

En las culturas prehispánicas de México se conoce su uso desde la cultura Olmeca en el Golfo de México alrededor del 1.000 a. C., y fue utilizado por los mayas y teotihuacanos para ungir a sus muertos; prueba de ello son los restos de algunos enterramientos teotihuacanos como la reina Roja y el rey Pakal de Palenque, que son ampliamente conocidos en el Estado de Chiapas.

En el pasado nos precedieron autores como Román Piña Chan, Doris Heyden, Jaime Litvak, quienes hicieron notar el vínculo del cinabrio con el color rojo de la sangre. Sin embargo, Alberto Herrera (1994) y, luego, Elizabeth Mejía, siguiendo la línea de sus predecesores (Velasco 1978), han enfatizado que el cinabrio es el único mineral en la naturaleza que en sus propiedades naturales cambia de color de rojo brillante a negro cuando es expuesto al medio ambiente, al igual que la sangre cuando se seca (Herrera 1994; Mejía 2010). Por ello, para las culturas prehispánicas fue de un valor sagrado,

* Artículo seleccionado del conjunto de ponencias presentadas en la Primera Reunión Internacional sobre Minería Prehispánica en América (PRIMPA), realizada en San Pedro de Atacama, Chile, diciembre 2010. Este manuscrito fue evaluado por investigadores externos y editado por Diego Salazar y Valentina Figueroa, en su calidad de editores invitados de la Revista.

1 Post. Centro INAH Querétaro. Andrés Balvanera 2.Centro, Querétaro, CP 76000, Querétaro, México.toluquilla2000@ yahoo.com.mx; ranasmex@gmail.com 
además de un símbolo de riqueza, poder y con propiedades mágicas, relacionadas con los dioses del inframundo. Así, el polvo de cinabrio fue depositado como ofrenda dentro de conchas y vasijas, como también para ungir el cadáver de personajes prominentes en el México prehispánico. Considerando que dentro de la Sierra Gorda existen yacimientos de sulfuro rojo de mercurio, denominado como "granate" o "cinabrio", la población antigua de la zona compartió los mismos conceptos de creencias y sus pobladores se dieron a la tarea de localizarlo, extraerlo y prepararlo para participar con él en los sistemas de intercambio de larga distancia.

\section{El Proyecto}

\section{Ámbito regional}

En el presente trabajo se exponen los resultados de interpretación por la combinación de dos proyectos diferentes. Por una parte, los recorridos de prospección orientados a la localización y registro de sitios arqueológicos y labores mineras realizadas entre 1984 y 2008. Esto generó un inventario de 146 localidades arqueológicas prehispánicas distribuidas en una superficie aproximada de $170 \mathrm{~km}^{2}$, realizando un recorrido sistemático exhaustivo en $42 \mathrm{~km}^{2}$ (Figura 1).

El otro proyecto se inicia en el 2004, con el objetivo de dar respuesta a diversos planteamientos como:

... ¿1. Existió contaminación de mercurio en el medio ambiente y afectó éste a la población prehispánica? 2. En contraste, ¿existen efectos toxicológicos por mercurio en la población actual, minera o no minera? 3. ¿La actividad minera de mercurio ha afectado la calidad actual de los sistemas terrestres (agua, suelo, aire, planta) y en qué proporción?... (Hernández 2009:1).

Tomando al mercurio como eje del proyecto, se integran en un trabajo interdisciplinario dos aproximaciones vinculadas con el aspecto humano: las ciencias de la salud, específicamente la toxicidad actual y la bioacumulación prehispánica; así como las ciencias sociales, para conocer el impacto sociopolítico y económico desde la antropología y arqueología. Por otra parte, se suman los estudios de la naturaleza para analizar los componentes principales, que se articulan con la biogeoquímica del Hg y para establecer el ciclo BGQ, la especiación del $\mathrm{Hg}$ y los análisis químicos. Asimismo, se incluyen los sistemas terrestres para estudiar el agua, el suelo, el aire y las plantas, además de las ciencias de la tierra con la finalidad de conocer el ciclo del gas radón y el marco geológico, entre otros aspectos (Hernández 2009).

Este proyecto acontece en el marco del convenio bilateral entre México y Hungría, específicamente entre el Centro de Geociencias en el Campus Juriquilla en Querétaro de la Universidad Autónoma de México (UNAM), con el apoyo del CONACYTHKTH (2008-2009), y el Instituto Geológico de Hungría (MAFI) y las Universidades de Miskolc y Szent István. En el equipo de trabajo también participan investigadores de la Universidad Autónoma de Querétaro, de la Universidad Autónoma del Estado de México, Universidad Autónoma de Guanajuato y la Facultad de Química de la UNAM. Por último, se cuenta con la colaboración del Instituto Nacional de Antropología e Historia (INAH) que aportó con los restos óseos antiguos y apoyo financiero para el procesamiento de estas muestras. Esta colaboración se organizó en un seminario que presentó resultados en tres momentos, el último en 2009 y del que se deriva este trabajo. Nuestro trabajo une los resultados de los dos proyectos y el resultado de los muestreos y determinación de $\mathrm{Hg}$ total en sedimentos, elaborado por el equipo encabezado por el doctor Gilberto Hernández.

La metodología seguida fue de colectas de suelos y sedimentos asociados a minas de diversas épocas, así como el muestreo aleatorio estratificado a lo largo de cauces de agua. Todo esto fue procesado en el Centro de Geociencias de la UNAM y, posteriormente, se realizaron estudios de estadística multivariante (ANOVA) y la aplicación de análisis de información geográfica para determinar y graficar la concentración de mercurio. Todo ello con miras a determinar áreas con mayor concentración y verificar si son nocivos para el medio ambiente y la salud pública (Hernández 2009).

Por otra parte, el proyecto encabezado por el arqueólogo Alberto Herrera ha logrado un mapa de distribución de localidades arqueológicas y minas de diversas épocas y, junto con la arqueóloga Elizabeth Mejía, proponen una jerarquización de asentamientos que van desde un poblado mediano hasta un pequeño caserío junto a una mina. También proponen que 


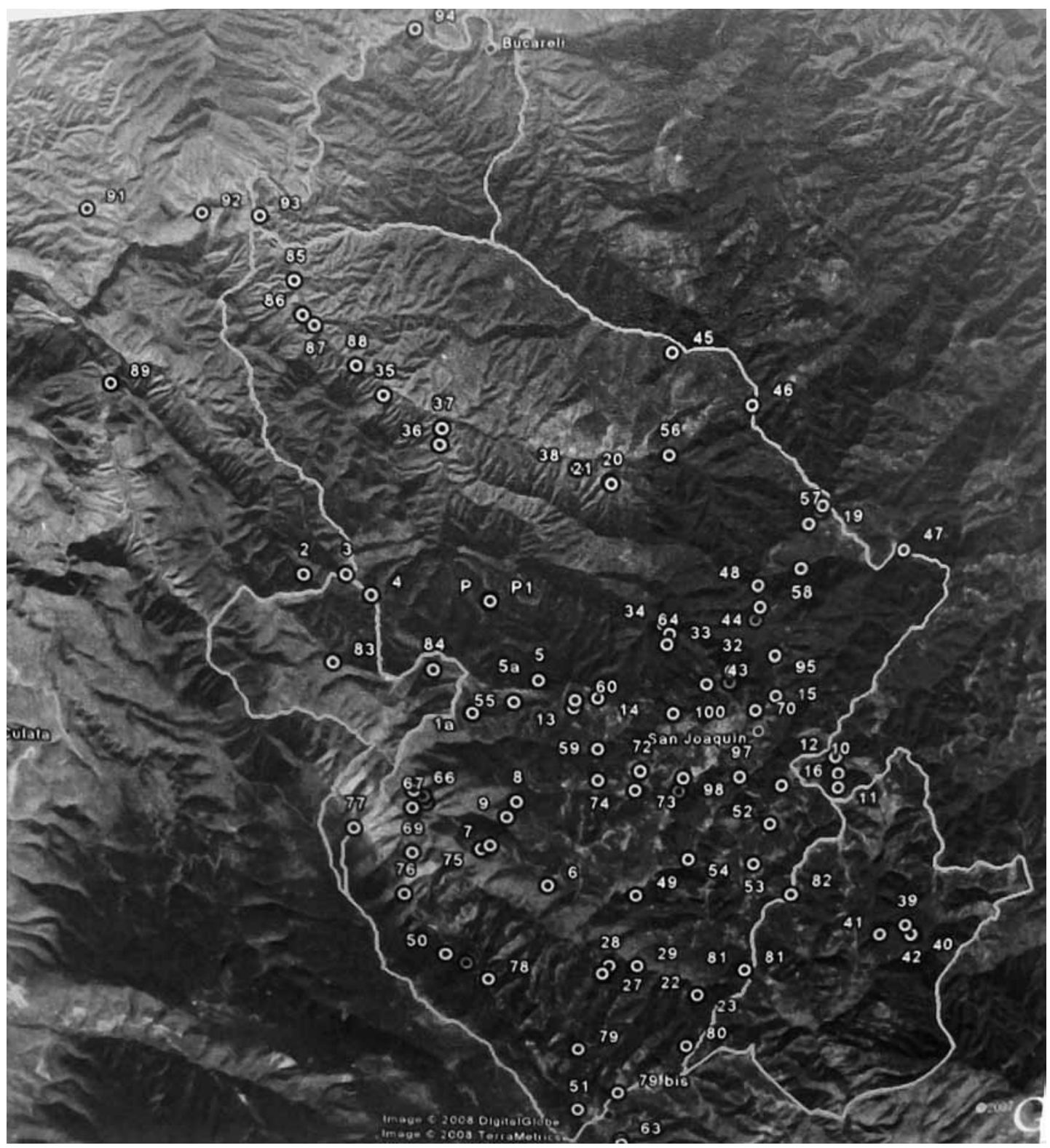

Figura 1. Puntos de muestreo para $\mathrm{Hg}$ en el área de estudio.

Soil and sediment sampling points for $\mathrm{Hg}$ determination in the area under study.

existen cuatro asentamientos de mayor importancia en la región: Toluquilla, Ranas, San Joaquín Ranas y El Doctor. Todos con una posición estratégica, que mantienen un control visual directo de las unidades menores y administran de forma directa los recursos que existen en su entorno (Herrera 2007, 2009; Mejía 2010).

Particularmente, uno de nosotros se enfoca al análisis de cada sitio y su posición espacial enfatizando como cada uno corresponde a una cuenca hidrográfica diferente: Toluquilla se encuentra en la cuenca Pondejhe; Las Ranas en la cuenca Agua de Venado; en la cuenca Agua de León el sitio que domina es San Joaquín Ranas -hoy poblado de San Joaquín- y para la cuenca Arroyo Grande es la localidad prehispánica de El Doctor. Por otra parte, la arqueóloga Mejía se enfoca al análisis óseo para comprobar si los individuos enterrados en 
Toluquilla tuvieron contacto con mercurio, y si se observa la presencia de este mineral en los huesos prehispánicos (Mejía 2010).

De forma general, Herrera propone dos variantes en el patrón de asentamiento de la subregión serrana al sur de la Sierra Gorda, una en la zona alta y donde se observa mayor humedad, y otra, en las áreas secas donde la sombra de lluvia provoca precipitaciones menores. En general, ocupan diferentes nichos ecológicos donde los recursos son variables. En primer término, en la zona húmeda y alta se diferencian cuatro niveles jerarquizados con arquitectura monumental en los asentamientos; mientras que en la segunda variante adaptativa, las zonas secas, estos se distribuyen en forma lineal con un patrón disperso y con arquitectura de habitaciones de materiales perecederos, áreas de actividad y sin construcciones en piedra, por ello no se pueden establecer los cuatro niveles (Mejía 2010).

El patrón de asentamiento macrorregional de la zona húmeda tiende a ser agrupado (clusters) en su composición interna, de baja densidad en relación con los sitios vecinos, para las regiones húmedas (precipitación pluvial promedio superior a los $800 \mathrm{~mm}$ anuales), y tienen, además, un radio promedio de interacción entre las unidades arqueológicas de $700 \mathrm{~m}$, con un traslape mínimo y una visual directa. Al graficar estas localidades en un plano topográfico, es claro que existe una tendencia a la agrupación de sitios en torno a los principales yacimientos minerales de la región, y a ubicar los asentamientos en las áreas de ecotono, de modo que puedan obtener la mayor diversidad de recursos en distancias mínimas (Herrera 1991).

Por otro lado, en la porción seca de la sierra, con precipitación pluvial promedio menor a $700 \mathrm{~mm}$ anuales, la composición interna de las unidades arqueológicas es el patrón nucleado; entre los diversos sitios de la región es más disperso, esto es, con un radio mínimo de $1,2 \mathrm{~km}$ de distancia al punto medio entre sitios. Así, la distribución regional adquiere la forma de patrones lineales que siguen los cursos permanentes de agua, posiblemente, porque en la porción semidesértica la estrategia de ocupación estuvo orientada a un control de las fuentes permanentes de agua por los asentamientos más grandes; posteriormente se agrupan en torno a los yacimientos de rocas y minerales; y, en un tercer nivel, en sitios estratégicos sobre las rutas de acceso (Herrera 1991).

\section{Colección ósea}

En 1993 se propuso un trabajo multidisciplinario: el proyecto Toluquilla. Uno de sus objetivos principales fue localizar y excavar entierros humanos, para obtener estudios diversos desde un enfoque biocultural, para así tratar de entender el papel de la salud y su relación dinámica con el medio ambiente, la población y sus actividades económicas, como medidas de adaptación que condicionaron e influenciaron las condiciones biológicas y culturales (Márquez y Hernández 2006:19-20). Para eso se analizó el sexo, la edad, el estado de salud, la dieta, las patologías y entesopatías que mostraban los individuos. Todo esto, para conocer si la población enterrada en Toluquilla fue la misma que trabajó en las minas cercanas o tuvieron que ver en el procesamiento del cinabrio (Mejía, 1994).

En 17 años se han excavado 28 entierros individuales y múltiples, lo que lleva a una colección de los restos de 198 individuos (Mejía 2002, 2003, 2004, 2005). A esto, le sumamos un entierro de la zona arqueológica de Ranas, que fue producto de un rescate arqueológico durante 1992 (Herrera 1993).

La labor minera significó diversos niveles de exposición al mineral y el trabajo impactó de diversas formas al sistema óseo con efectos diferenciales al cuerpo. En primer lugar, debemos considerar que cuando los mineros hallaban las vetas y penetraban en la tierra lo hacían martillando y fracturando las rocas para seguir el filón y conseguir un espacio de circulación. Extraer el mineral de la veta implicó el golpeteo constante con mazos y martillos de piedra, lo que representa impactos permanentes en muñecas, codos y hombros, además de exponerse a respirar el polvo en todo el tiempo de perforación y, eventualmente, encontrar lugares de acumulación de gases que, al ser liberados, debieron provocar en ocasiones la muerte instantánea por intoxicación aguda de los mineros. Extraer el mineral de las profundidades se realizó por medio de la carga con mecapal ${ }^{1}$, lo que produce una presión en tobillos, rodillas, columna vertebral y en la frente, por efecto del peso transportado en forma constante. Ya afuera de la mina, el material se transportó a los sitios cercanos, o bien en el patio de la mina, donde se realizaba el trabajo de molienda.

La metodología propuesta consideró cinco aspectos: 
1. Garantizar que los residuos de metales analizados no se contaminaron por transmisión debido al contacto con sedimento que contenga metales. Por esto, se optó por tomar muestras del suelo arqueológico de los sitios de Toluquilla y Ranas, ya que si el contenido de mercurio del sitio arqueológico es menor al que presentan los huesos, es improbable que la contaminación venga del sedimento.

2. Utilizar porciones corporales de alta dureza evitando transmisión de metales del suelo, por lo que se eligió un diente, porciones de cráneo preferentemente en la porción basal y tejido esponjoso de huesos largos de cualquiera de las extremidades.

3. Para la selección de los individuos, la doctora Martha Pimienta, que analizó parte de la colección, propuso que se examinara a todos los individuos de una misma estructura, buscando la que presentó la mayor diversidad en contextos, el mayor número de individuos y la mayor diversidad en las edades. Se consideraron en primer término, los entierros e individuos de dos edificios: esto incluye toda la variabilidad de edades, los dos sexos y los individuos con ofrenda y sin ella. Los estudios de metales se iniciaron mientras se realizaba el estudio antropofísico, de manera que los resultados de ambos trabajos se tendrían simultáneamente para así poder analizar el contenido de metales junto con los resultados de los datos generales de los individuos, indicadores dentales (caries, sarro, abscesos, hipoplasia, pérdida dental, desgaste y reabsorción ósea), nutrición (hiperostosis y criba orbitalia), enfermedades infecciosas, periostitis, osteofitosis, traumatismos, osteoartritis y entesopatías (Márquez y Hernández 2006:20).

4. Se propuso un trabajo analizando la muestra en dos laboratorios diferentes: uno, en el Centro de Geociencias de la Universidad Nacional Autónoma de México, Campus Juriquilla, utilizando un Espectrómetro de masas y Difracción de Rayos X. Posteriormente, esperamos que se realizara el análisis a las mismas muestras con el uso de un AMA-254 (Advanced Mercury Analyser) en el Instituto Geológico de Hungría, institución que posee la certificación mundial de la Comunidad Europea (Hernández et al. 2005).
5. Se analizaron 11 metales, que por la interacción eléctrica de iones y átomos permiten enlaces del ciclo biogeoquímico de minerales y cadenas, que en la Unión Europea se han estudiado desde hace tiempo (Salminen 2005).

Para la primera parte del análisis, se eligieron entierros primarios de adultos, los más completos posibles. Posteriormente infantes y adolescentes, disminuyendo el tamaño de muestra y se concluyó con nonatos, reduciendo aún más el número y además se eliminaron los dientes.

En total se analizaron 37 individuos mostrados en la Figura 2, donde se presenta una tabla que se ejemplifica con un personaje de cada edad para evidenciar las diferencias de contenido de mercurio en cada porción analizada, esto es: cráneo, diente y hueso largo.

Las Figuras 3, 4 y 5 muestran los resultados de mercurio, arsénico y plomo, cada una en una tabla donde el contenido de cada metal se presenta en orden ascendente, desde nonatos hasta adultos, con el mismo acomodo de la Tabla 1, que muestra la edad de los individuos. Cada tabla muestra en color ocre a los nonatos, en color verde a los infantes y en color azul a los adultos y el caso de Ranas se ubica en el extremo derecho de la tabla.

\section{Análisis de Resultados}

\section{Ámbito regional}

En un área de $170 \mathrm{~km}^{2}$ la clasificación de asentamientos es (Figura 6):

- Existen tres sitios de rango 1 (Ranas, San Joaquín Ranas y Toluquilla), importantes por su escala, número de estructuras, complejidad de diseño urbano y diversidad en materiales. Además, todos se ubican por encima de los $2.350 \mathrm{~m}$.

- Hay tres asentamientos de rango 2 (San Antonio, El Deconí y El Doctor), todos ellos ubicados en posiciones estratégicas de pasos regionales y dominio visual importante. Se localizan entre las cotas de 2.300 y $2.750 \mathrm{~m}$.

- El rango 3 está representado por 36 unidades de asentamiento, son permanentes y cuentan con estructuras habitacionales. Su emplazamiento, por lo general, está asociado a las zonas de transición ecológica y dominio visual a otras unidades de 


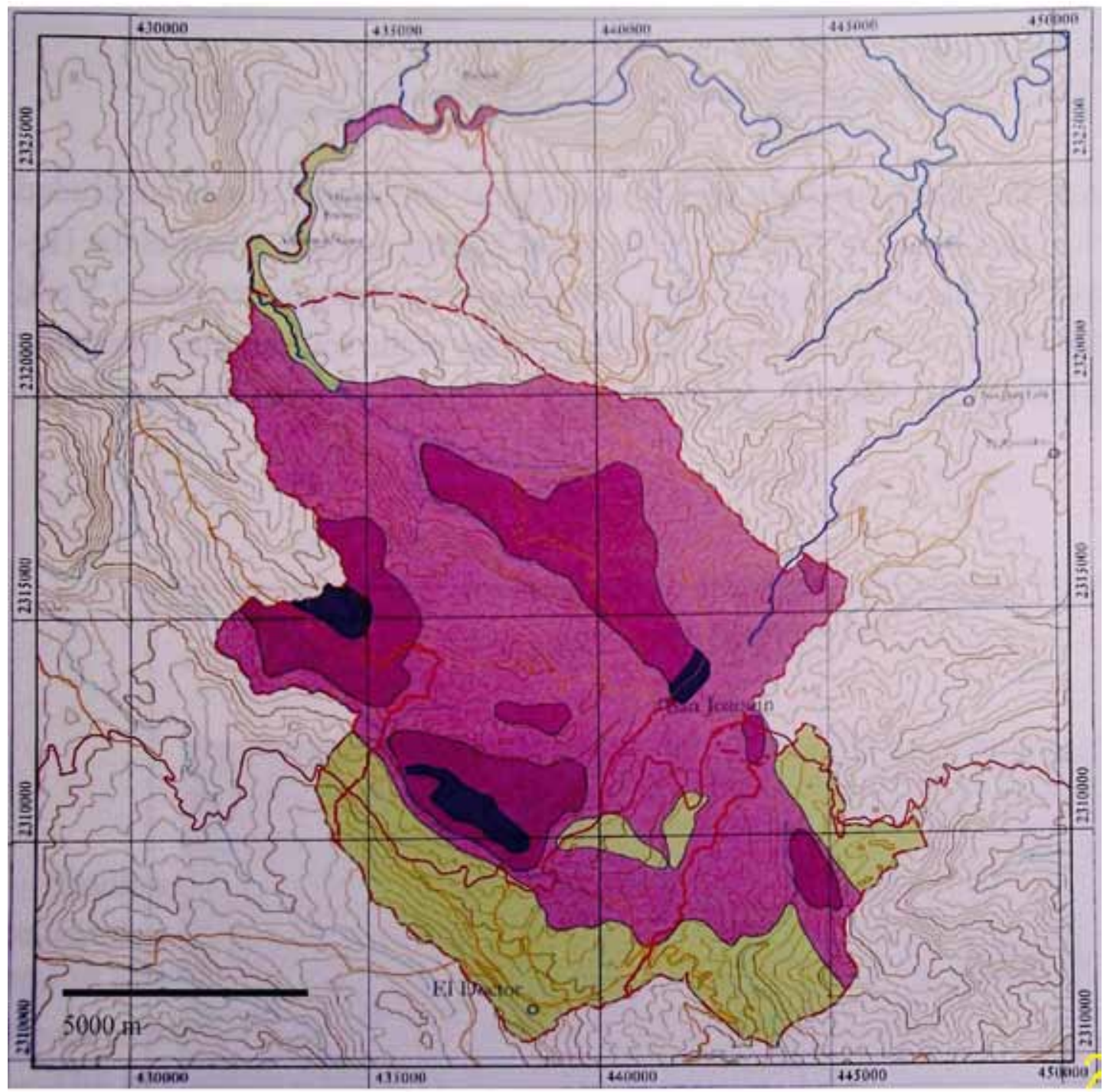

Figura 2. Mapa de distribución de $\mathrm{Hg}$ y de sitios arqueológicos.

Total Hg distribution map with archaeological sites overlap.

igual o menor rango, aunque también, con vista franca hacia uno de los asentamientos de rango 2. Por su posición topográfica, se les detecta desde los 850 hasta los $3.000 \mathrm{~m}$ de altitud.

- Las unidades de menor tamaño, o de rango 4, ocupan posiciones topográficas y ambientales muy diversas, pero siempre guardando un nexo visual con alguna unidad de rango 3 . En total, son 59 lugares clasificados dentro de este rango que están asociados a unidades de explotación de los recursos regionales y sus rasgos arquitectónicos son muy simples y difíciles de localizar, como las nivelaciones, plataformas y terrazas. La mayoría de las obras mineras de baja producción se encuentran en este rango (Figura 7).

Estos yacimientos se encuentran en 12 cuencas que son: Río Extoraz, Arroyo Gatos, Azogues, Rancho Quemado, Sombrerete, Zahurda, Maconi, Planes, Agua de Venado, Agua de León, Arroyo Grande y Pondejhe (Figura 7). Integrando la información de los dos proyectos en la Figura 1, se presentan los puntos muestreados y en la Figura 8 se expone un mapa donde se grafican en colores los valores medios de la presencia de mercurio en los sedimentos. 
Tabla 1. Muestra de individuos ordenada por entierro, edificios y edad.

Individual sample sorted by burial, building and age.

\begin{tabular}{cccc}
\hline & Individuo & Edad \\
\hline Entierro 13 a & Edificio 27 & $\mathrm{W}$ & 25 \\
& $\mathrm{~T}$ & 50 \\
\hline & $\mathrm{C}$ & 4 \\
& $\mathrm{D}$ & 16 \\
& $\mathrm{~L}$ & 18 \\
& $\mathrm{M}$ & 27 \\
& $\mathrm{~V}$ & 27 \\
& $\mathrm{U}$ & 33 \\
& $\mathrm{R}$ & 45
\end{tabular}

\begin{tabular}{ccccc}
\hline Entierro 13 c & Edificio 27 & $\mathrm{~V}$ & 1 \\
\hline Entierro $13 \mathrm{~d}$ & Edificio 27 & $\mathrm{~N}$ & 26 Semanas \\
\hline
\end{tabular}

\begin{tabular}{|c|c|c|c|}
\hline \multirow{5}{*}{ Entierro 14} & \multirow{5}{*}{ Edificio 27} & $\mathrm{~F}$ & 36 Semanas \\
\hline & & A & 1,5 \\
\hline & & $\mathrm{B}$ & 1,5 \\
\hline & & D & 1,5 \\
\hline & & $\mathrm{C}$ & 4 \\
\hline \multirow{12}{*}{\multicolumn{2}{|c|}{ Entierro 17 Edificio 24}} & $\mathrm{~F}$ & 1,5 \\
\hline & & $\mathrm{L}$ & 4,5 \\
\hline & & D & 6 \\
\hline & & I & 7 \\
\hline & & $\mathrm{N}$ & 7,5 \\
\hline & & $\mathrm{H}$ & 9 \\
\hline & & M & 11 \\
\hline & & $\mathrm{C}$ & 24 \\
\hline & & $\mathrm{E}$ & 35 \\
\hline & & $\mathrm{G}$ & 47 \\
\hline & & $\mathrm{J}$ & 55 \\
\hline & & $\mathrm{K}$ & 55 \\
\hline \multicolumn{2}{|c|}{ Entierro 20 Edificio 24} & A & 1,5 \\
\hline \multirow{2}{*}{\multicolumn{2}{|c|}{ Entierro $24 \quad$ Edificio 24}} & $\mathrm{~A}$ & 23 Semanas \\
\hline & & $\mathrm{B}$ & 25 Semanas \\
\hline \multirow{5}{*}{ Entierro 25} & \multirow{5}{*}{ Edificio 27} & $\mathrm{O}$ & 2 \\
\hline & & Q & 4 \\
\hline & & $\mathrm{K}$ & 25 \\
\hline & & $\mathrm{I}$ & 27 \\
\hline & & $\mathrm{J}$ & 27 \\
\hline \multicolumn{2}{|c|}{ RANAS } & A & 35 \\
\hline
\end{tabular}

Tabla 2. Valores representativos del contenido de $\mathrm{Hg}$ total por unidad muestreada en función de su clasificación por uso. Measured Values for total $\mathrm{Hg}$ in sediments and soil samples (adapted from Hernández 2009).

\begin{tabular}{lc}
\hline \multicolumn{1}{c}{ Localidad } & Valor de $\mathrm{Hg}$ \\
\hline Mina prehispánica + mina moderna & $4,164 \mathrm{mg}^{*} \mathrm{~kg}^{-1}$ \\
Azogues & \\
Mina moderna de Ovejas & $2,000 \mathrm{mg} * \mathrm{~kg}^{-1}$ \\
Mina Moderna Santa Fe & $1,448 \mathrm{mg} * \mathrm{~kg}^{-1}$ \\
Mina prehispánica Canoas, La Esperanza & $164 \mathrm{mg} * \mathrm{~kg}^{-1}$ \\
Suelo de parcela & $91,77 \mathrm{mg} \mathrm{kg}^{-1}$ \\
Toluquilla (suelo arqueológico) & $79,2 \mathrm{mg} * \mathrm{~kg}^{-1}$ \\
Ranas (suelo arqueológico) & $35 / 55 \mathrm{mg} * \mathrm{~kg}^{-1}$ \\
Terrero de mina moderna & $28,50 \mathrm{mg} * \mathrm{~kg}^{-1}$ \\
Suelo natural (Hernández et al. 2009) & $0,052-13 \mathrm{mg} * \mathrm{~kg}^{-1}$ \\
\hline
\end{tabular}

En la Figura 8, donde se muestran los valores de mercurio, podemos observar como los valores más bajos de mercurio se muestran en color verde con valores que van de 0 a $2,5 \mathrm{mg}^{*} \mathrm{~kg}^{-1}$; mientras que en color rosa claro, en la superficie más extensa, el valor va de 2,5 a $25 \mathrm{mg}^{*} \mathrm{~kg}^{-1}$; luego, en color rosa intenso el valor va de 25 a $250 \mathrm{mg}^{*} \mathrm{~kg}^{-1}$ (es en este punto donde se localizan los asentamientos de Ranas, Toluquilla y El Doctor). Con el color más oscuro -morado- se representan valores superiores a 250 y llegan hasta $4000 \mathrm{mg}^{*} \mathrm{~kg}^{-1}$. Todo ello, ya que se reportan los siguientes valores para sedimentos de minas y los resultados de las muestras de los sitios arqueológicos (Hernández 2009), Tabla 2.

De todo esto, es relevante que las minas modernas tienen valores que rebasan los $2,000 \mathrm{mg}^{*} \mathrm{~kg}^{-1}$; los valores máximos los presentan aquellos lugares con una acumulación de ocupaciones y, por ello, con sobreposición, lo que se evidencia al máximo en Azogues con 4,164 $\mathrm{mg}^{*} \mathrm{~kg}^{-1}$, aunque una mina prehispánica sin la reutilización intensiva presenta valores de $164 \mathrm{mg}^{*} \mathrm{~kg}^{-1}$.

Fue notorio como en unidades agrícolas - parcelas-y los sitios arqueológicos, donde esperábamos valores similares a los del suelo natural el valor de $\mathrm{Hg}$ fue de entre 35 y $100 \mathrm{mg}^{*} \mathrm{~kg}^{-1}$, datos similares a los que se observan en los terreros de desecho de las minas modernas.

Desde una perspectiva más general, el trabajo realizado por el equipo del Centro de Geociencias de la UNAM, encabezado por el Dr. Gilberto Hernández, realiza un muestreo regional que constó en el registro de más de 100 lugares, con una estrategia orientada a entender los patrones y 


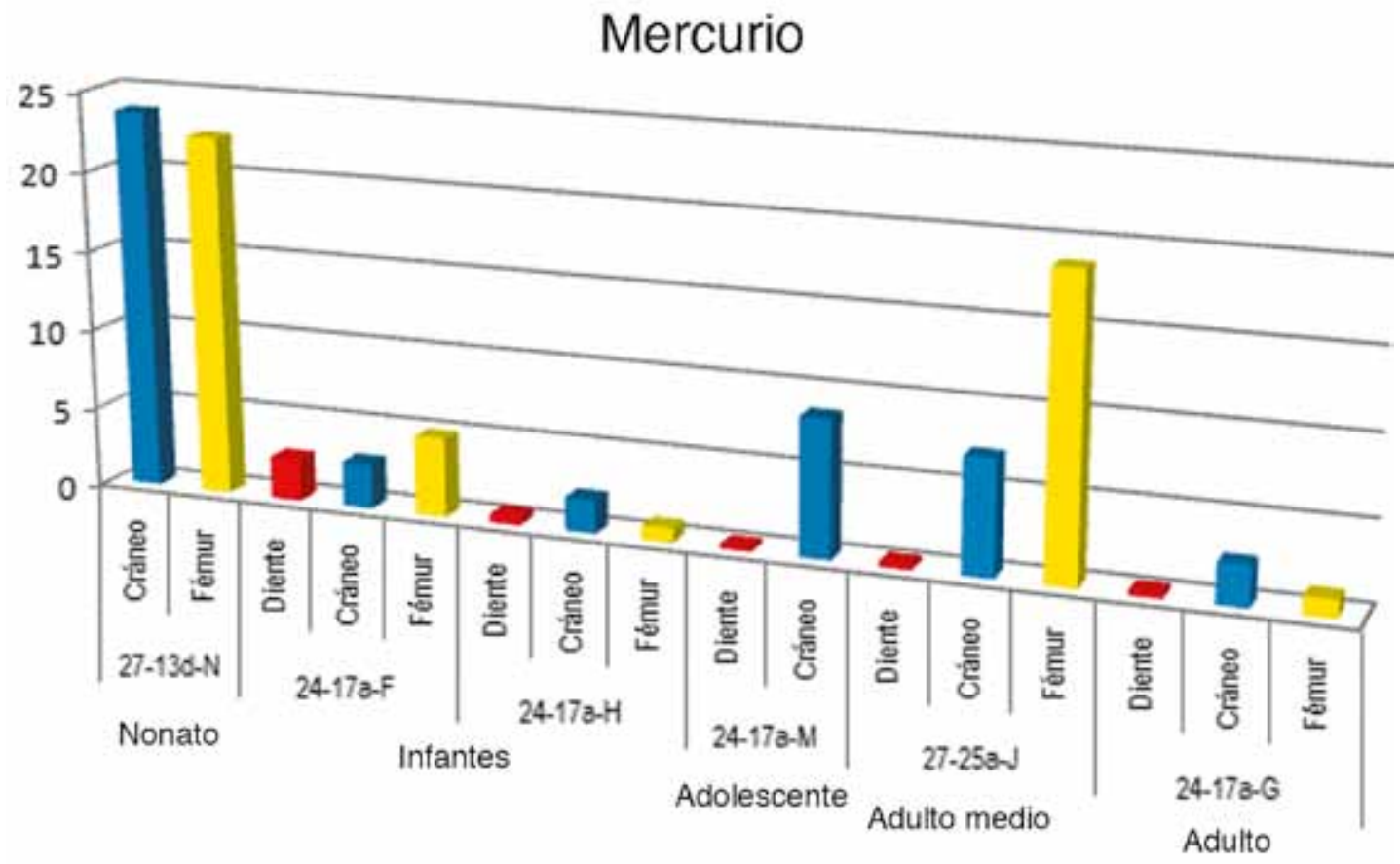

Figura 3. Ejemplo de seis individuos, cada uno muestra un representativo de la edad y los resultados de mercurio en tres porciones muestreadas.

Example of six individuals, each one are representative of the age and the column results for total mercury for each body part sampled.

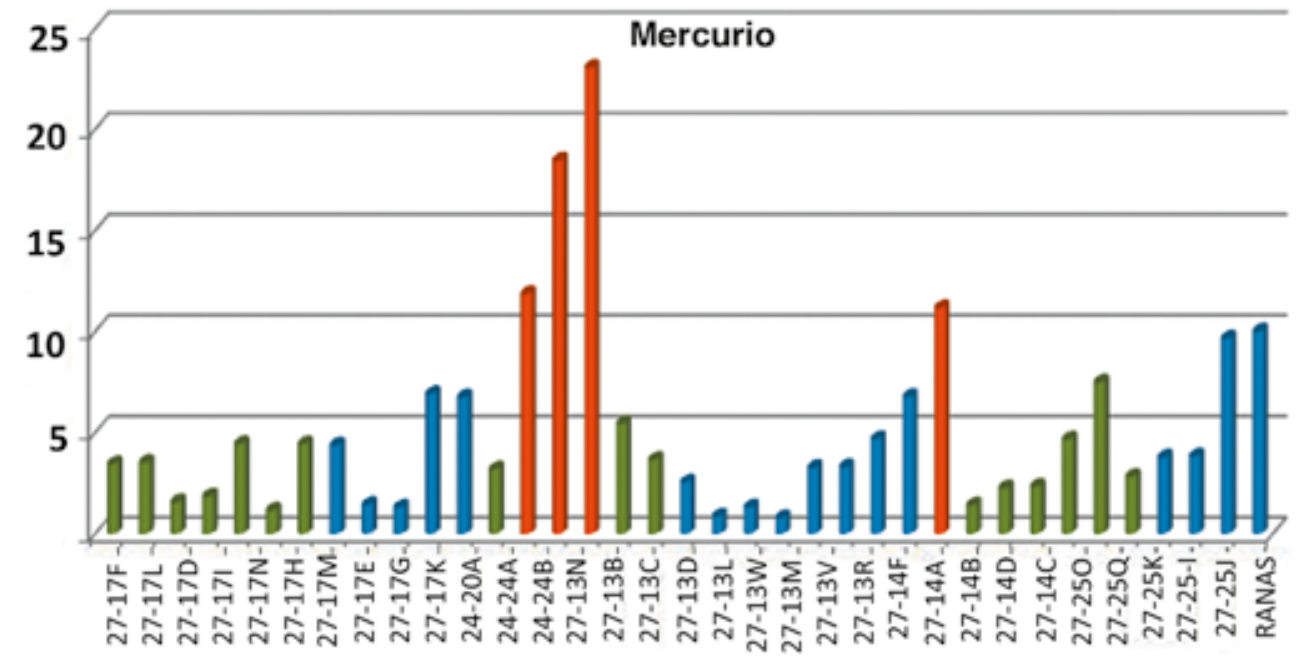

Figura 4. Contenido de mercurio en huesos humanos.

Measurement of total $\mathrm{Hg}$ in human bones.

condiciones de dispersión del $\mathrm{Hg}$ por los procesos físico-químicos del medio ambiente. Resultado de este intenso trabajo, publica un mapa de la distribución de $\mathrm{Hg}$ total en suelos, sedimentos y terreros (Hernández 2009).
El mapa de la Figura 8, en sí mismo constituye un aporte a los estudios de las regiones mineras del $\mathrm{Hg}$ que han sostenido una explotación humana por más de 2.000 años. Sin embargo, nosotros lo combinamos con la distribución de sitios, visibles 


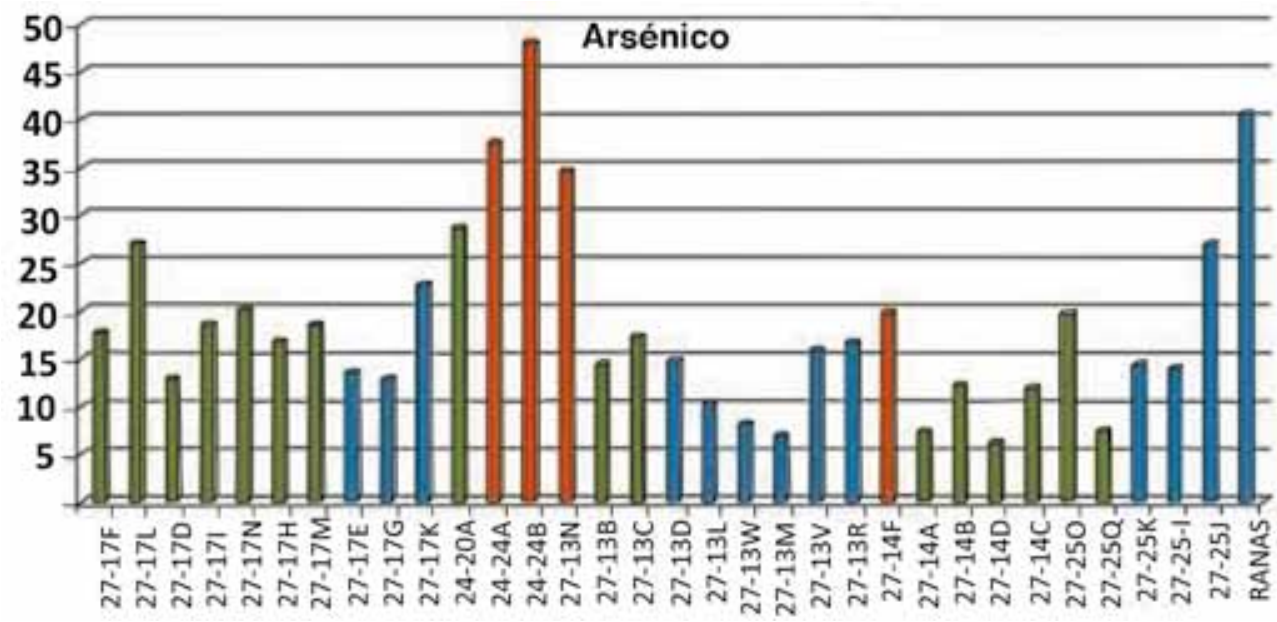

Figura 5. Contenido de arsénico en huesos humanos.

Quantifications for arsenic in human bones.

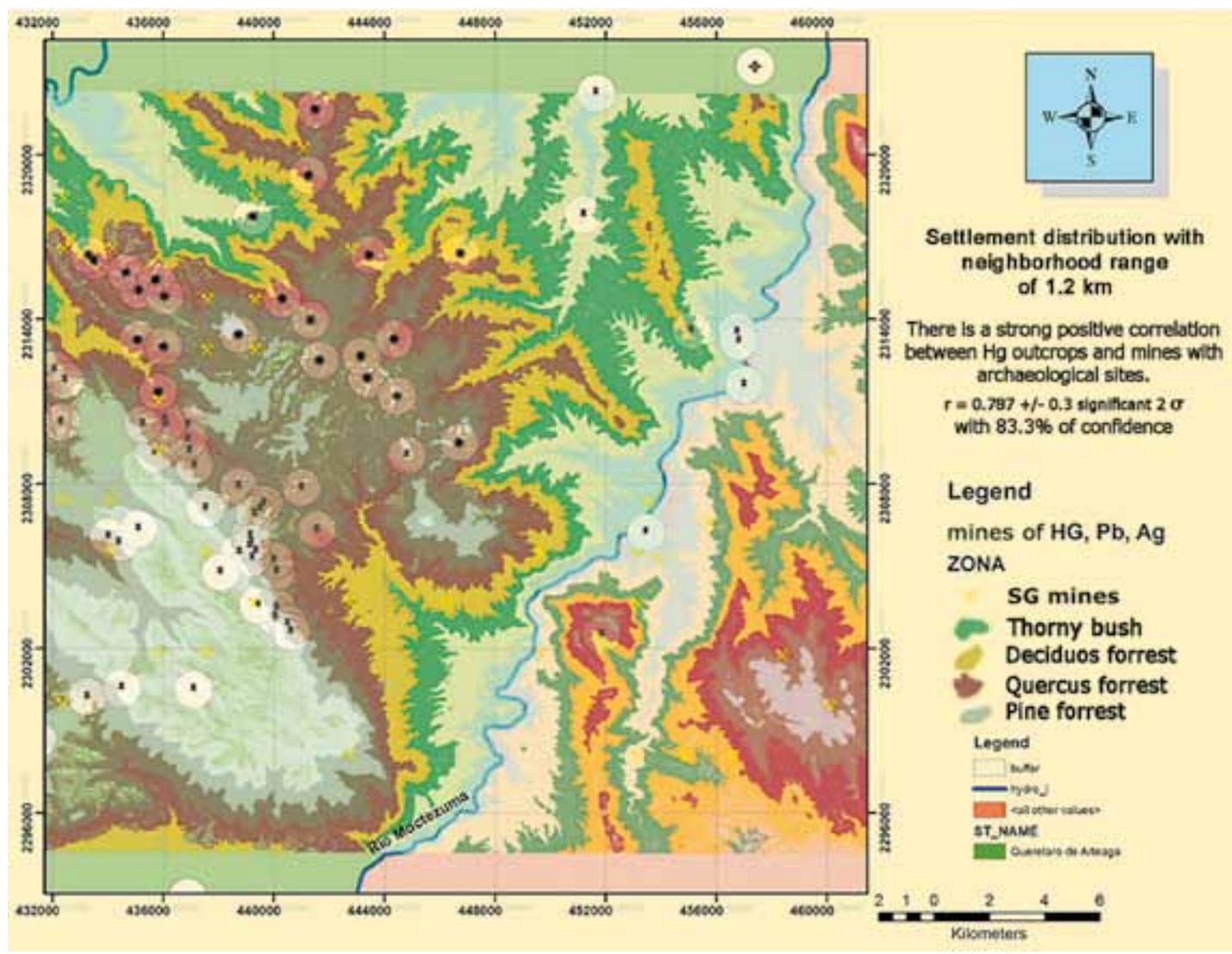

Figura 6. Análisis geográfico de puntos, los asentamientos se ubican en las zonas de transición ecológica marcadas con las gradaciones de color.

Geographic point analysis. Settlements are located at ecological transition zones marked with gradations of color. 


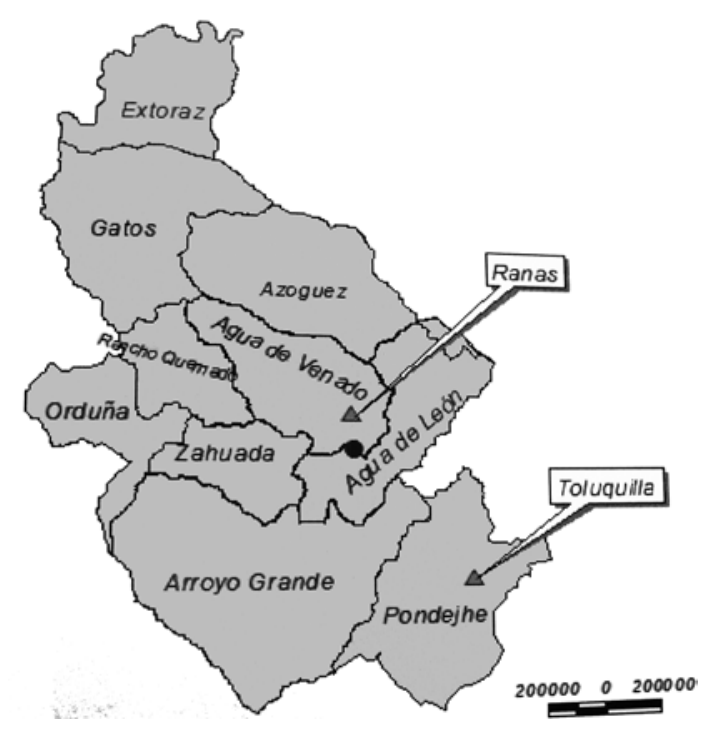

Figura 7. Plano de situación de la Sierra Gorda de Querétaro y Microcuencas en el área de estudio (Hernández 2009a). Location map for Sierra Gorda and Micro-basins in the area under study (Hernández 2009a).

en la Figura 2, pudiéndose percibir cuatro rangos de graficación para los valores de la concentración de $\mathrm{Hg}$, excluyendo áreas con pobre representación de datos, los mismos que se analizaran con el traslape de la distribución de asentamientos arqueológicos registrados.

En el rango superior a $250 \mathrm{mg} / \mathrm{kg}$ de $\mathrm{Hg}$ total (color púrpura) se detectan al menos tres zonas: una que se encuentra en la cuenca La Orduña, que se ve en la sección centro al oeste. Desde el punto de vista arqueológico sólo se cuenta con la referencia cercana con la mina Las Calabacillas.

La segunda zona corresponde al límite entre las cuencas de Agua de Venado y Agua de León, donde de forma central se ubica el sitio La Guadalupana y el conjunto de minas denominado Las Escaleras. Bordeando sus límites se encuentran dos de los asentamientos más importantes de la región: Zona Arqueológica Ranas -con 14 minas asociadas-y San Joaquín Ranas que controla directamente tres minas grandes en época antigua: Las Pilas, La Estrella y la Mina Prieta, asentamientos que controlan la explotación, beneficio y distribución del cinabrio en época prehispánica. El área delimitada en tercer lugar se localiza al pie del macizo Montañoso de El Doctor, correspondiendo a la cuenca Arroyo Grande, donde destaca la presencia de cuatro sitios de explotación: Mina La Fe o La Lana, Mina de Los Puerquitos, Mina de Guadalupe y Mina del Palo Santo. En total, hay cuatro asentamientos antiguos sobre áreas de valor superior a los $250 \mathrm{mg}^{*} \mathrm{~kg}^{-1}$ total.

El siguiente rango graficado refiere concentraciones de $\mathrm{Hg}$ total de 25 a $250 \mathrm{mg}^{*} \mathrm{~kg}^{-1}$ (color rosa). Congruentemente, las isolíneas rodean las tres zonas descritas con una mayor extensión, teniendo así para la primera, una delimitación que toca las cuencas La Orduña y Rancho Quemado, incluyendo dos sitios arqueológicos más. La segunda zona tiene una mayor dispersión sobre las microcuencas de Agua de Venado, Azogues y, de forma marginal, Agua de León; con esta dispersión, se incluyen 15 marcas arqueológicas más. La porción correspondiente a la cuenca Arroyo Grande es ocupada por otros siete sitios. En este nivel de concentración se graficaron otras cuatro áreas: en el extremo este la zona de Maravillas con un sitio arqueológico que es una porción de una cuenca que se extiende fuera del área de estudio; la subregión de Canoas cuya cuenca también posee un desarrollo fuera del área de muestreo, y, al límite norte de la microcuenca Pondejhe que incluye cuatro asentamientos prehispánicos. En la porción central de la cuenca $\mathrm{La}$ Zahúrda hay dos unidades de producción de $\mathrm{Hg}$ antiguas y, por último, pero no menos importante, está la demarcación hecha en los alrededores de la Zona Arqueológica Toluquilla con un rango 1 con cuatro marcas, de las cuales, una corresponde al sitio mismo y, otras tres, a minas prehispánicas de $\mathrm{Hg}$. En total, para las zonas con un contenido de $\mathrm{Hg}$ total se cuenta con 35 sitios.

Dentro de la misma figura el tercer rango de $\mathrm{Hg}$ total va de 2,5 a $25 \mathrm{mg}^{*} \mathrm{~kg}^{-1}$, se muestra en color rosa y es posiblemente el valor natural o de fondo de la región, ya que posee una distribución muy amplia en todas las microcuencas. Sobre esta porción se asientan un total de 38 sitios arqueológicos.

Con valores entre 0 y $2,5 \mathrm{mg}^{*} \mathrm{~kg}^{-1}$, total graficado en verde pálido, se observan cinco áreas: una en la desembocadura al río Extoraz y cuatro más que se concentran en la porción sur del área de estudio, que se ubican al norte de Esperanza, las inmediaciones de Pozos -Los Herrera, Nuevo San Joaquín-La Veracruz y, por último, una franja que se localiza sobre la cabalgadura de El Doctor y la sección sur de la microcuenca Pondejhe. Sobre los terrenos que tienen estas concentraciones mínimas de Hg total están 24 sitios antiguos. 


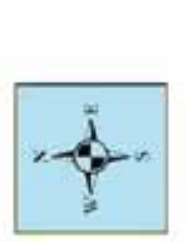

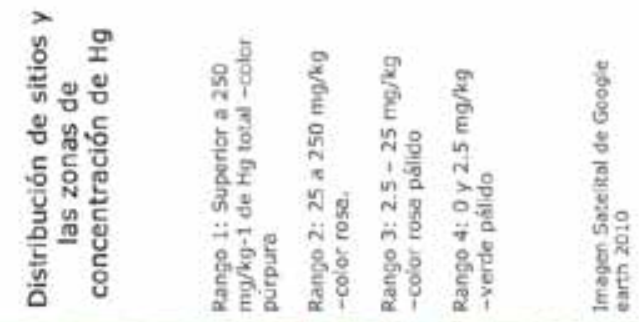
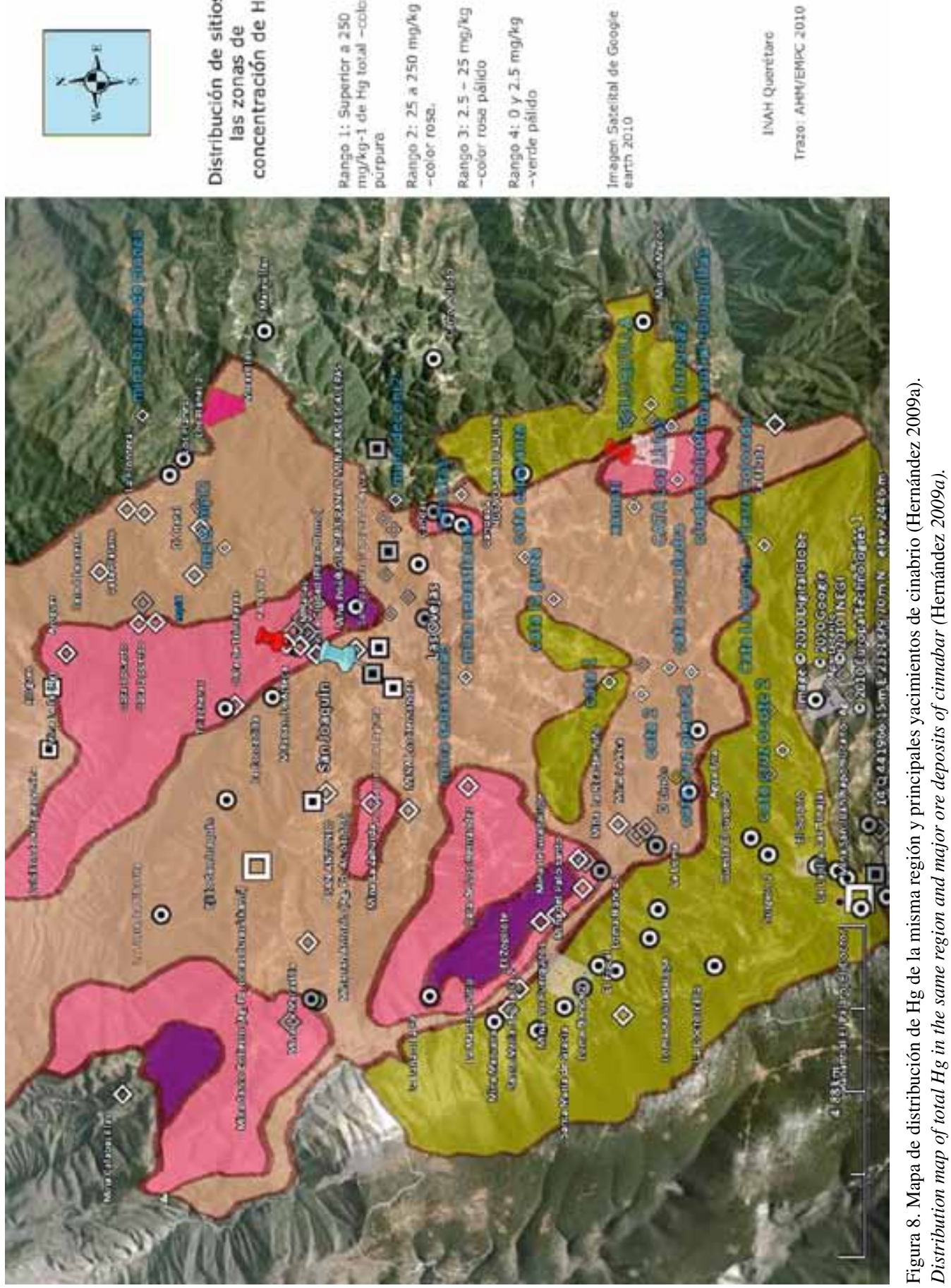


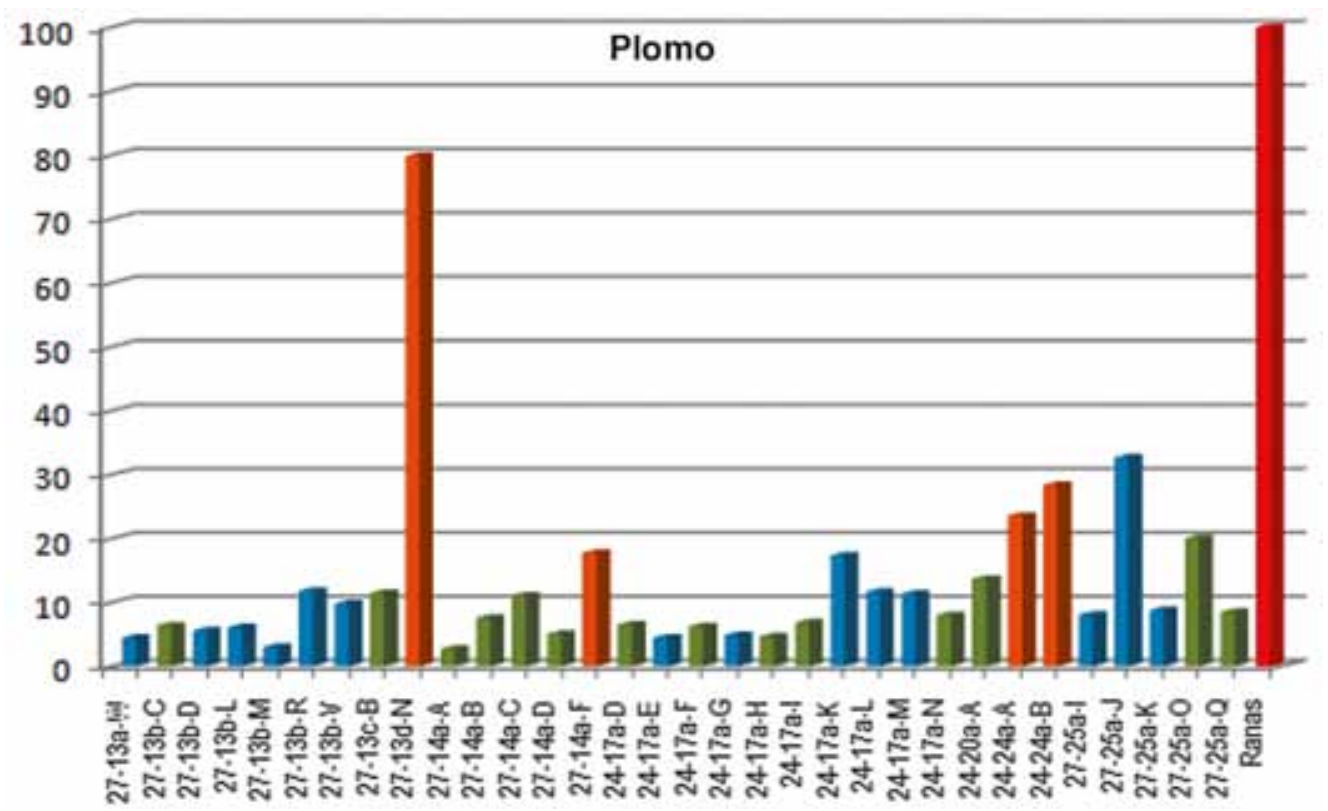

Figura 9. Contenido de plomo en huesos humanos.

Lead contents in human bones.

Desde el punto de vista arqueológico, la obra minera prehispánica se orientaba a la explotación de estas vetas, excavando el área mínima indispensable para que las personas se pudieran desplazar, de tal modo que dejaron túneles, en ocasiones, muy reducidos, irregulares en formas y muy torcidos en cuanto a su dirección, ya que seguían los plegamientos de la formación geológica.

Sumando el volumen extraído en cada mina de nuestra zona de estudio, obtenemos un volumen total de roca superior a los $11.900 \mathrm{~m}^{3}$, a los que si les asignamos un contenido básico promedio de cinabrio que sea de sólo el 1\%, nos enfrentamos a un volumen de $119 \mathrm{~m}^{3}$ de mineral, y sabiendo que cada metro cúbico pesa un mínimo de 8 toneladas, el total de la producción estimada sería de 952 toneladas que no están representados en los sitios serranos, ni en muchos de los sitios consumidores conocidos (Herrera y Mejía 2009).

\section{Ámbito específico: Colección ósea}

En la gráfica de la Figura 6 se observa un ejemplo de seis individuos de diferente edad y sexo que sirven para ejemplificar la distribución diferencial de mercurio en dientes, cráneos y huesos largos. En las Figuras 4, 5 y 9 se muestra el contenido de tres metales: mercurio, arsénico y plomo.
Destaca el que en toda la población existen valores altos, aunque los cuatro nonatos resaltan porque tienen los valores más elevados en todos los metales dentro de esta población, con valores de hasta $35,20 \mathrm{mg}^{*} \mathrm{~kg}^{-1}$ en arsénico y de 23,05 mg* $\mathrm{kg}^{-1} \mathrm{de}$ mercurio, cuando no debería pasar de $3 \mathrm{mg}^{*} \mathrm{~kg}^{-1}$ en arsénico y $1,5 \mathrm{mg}^{*} \mathrm{~kg}^{-1}$ de mercurio ${ }^{2}$.

Los niños menores también muestran valores muy altos, no así los adultos jóvenes, ya que el contenido aumentó al incrementarse la edad. Caso aparte es el individuo de Ranas que presenta los valores más altos, particularmente para el plomo que rebasa toda proporción al tener un valor de $973,40 \mathrm{mg}^{*} \mathrm{~kg}^{-1}$, por ello no se graficó en el valor real.

\section{Conclusiones}

En la porción sur de la Sierra Gorda, es un hecho que los habitantes antiguos generan un sistema de poblamiento orientado a controlar directamente los principales yacimientos de $\mathrm{Hg}$ existentes en la región. Este sistema de organización es complejo, ya que su estrategia adaptativa es generar un patrón de asentamiento semidisperso para aprovechar la biodiversidad regional, lo cual generó la edificación de tres grandes centros urbanos: Toluquilla, San Joaquín Ranas y Ranas. Es sorprendente que con 
una tecnología tan limitada (sólo instrumentos de piedra) hayan hecho un uso tan intensivo de los yacimientos de cinabrio, almagres y, probablemente, de los minerales de plomo existentes en la región.

De acuerdo con el estudio hecho por Hernández (2009), se determinó un valor de fondo a la concentración de $\mathrm{Hg}$ total y se detectaron las zonas de riesgo para la salud de la población contemporánea. Sin embargo, la información compilada en su estudio es importante analizarla con más detalle, vinculándola a los problemas socioculturales antiguos y contemporáneos. Desde la perspectiva arqueológica implica un análisis más fino ya que, como se estableció en el estudio del equipo de geociencias, el mercurio y sus compuestos tienden a no migrar y tener una tendencia acumulativa en los suelos y sedimentos. Los aportes culturales de la distribución del $\mathrm{Hg}$ total deben ser analizados en la escala de los asentamientos. Es importante graficar con mayor detalle el intervalo $250-2500 \mathrm{mg}^{*} \mathrm{~kg}^{-1}$ de $\mathrm{Hg}$ total, esto delimitará con mayor precisión los asentamientos antiguos que están vinculados con el beneficio y distribución del cinabrio, y no ponderar solo los lugares de extracción. Incluso, si se realiza en escala micro se pueden identificar las áreas de actividad específicas dentro de los sitios arqueológicos y relacionar estructuras particulares con estas actividades. Identificando estos nuevos patrones de distribución, se estará en condiciones de evaluar el aporte antrópico a la dispersión del $\mathrm{Hg}$ a escala regional y, a un nivel micro, determinar las áreas de actividad por el trasiego de la mena de mercurio.

Al combinar el mapa de distribución de Hg con el mapa de distribución de localidades arqueológicas, observamos que los valores de mercurio en las localidades arqueológicas se encuentran a un nivel superior que en las minas, esto, situándose en una posición topográfica por encima de las minas, de manera que no podemos suponer que se trata de un traslado ocasionado por efectos de la gravedad o escorrentía.

Establecida la relación entre las minas y los sitios arqueológicos ${ }^{3}$, vemos que la distribución que hoy observamos es el producto de actividad humana acumulada en la historia del lugar sumándose lo prehispánico, histórico y moderno y, además, se relaciona con el rango de los sitios y la función productiva que tuvo en el pasado. El valor promedio de la región -o valor de fondo- es más alto que en regiones donde no hay minas y no se practica la minería. Por otra parte, la distribución de los valores de mercurio total se observa como motas de valor medio alrededor de las minas modernas, de los sitios arqueológicos y de los poblados modernos en donde se practicó la minería. Cabe destacar, el que tanto los sitios arqueológicos como los poblados modernos se encuentran en lugares que topográficamente se ubican por arriba de las minas; por ello, no podemos pensar que la contaminación del suelo se debe al deslave del sedimento, sino al acarreo humano.

Este mapa también muestra como los valores más altos de mercurio no necesariamente siguen el curso de los arroyos (Figura 2) y con esto, no podemos asegurar que se trate de un arrastre pluvial $\mathrm{y}$, por ende, natural. Por el contrario, si muestra una cercanía con los lugares de alta mineralización, y aunque en la representación gráfica se homogeneizaron los datos de los valores máximos, las marcas son bien localizadas.

Respecto a los valores de mercurio en suelo, debe tenerse en cuenta que las muestras fueron tomadas de depósitos prehispánicos que estuvieron cubiertos por sedimentos que se acumularon en forma natural durante unos 500 años y que fueron retirados en los últimos años. Por ello, tenemos la certeza de que no fueron sometidos al medio, y la diferenciación de lugares también muestra como no pueden ser producto de la migración de los depósitos naturales a los arqueológicos. En consecuencia, son producto de contaminación y acumulación antrópica antigua. Con esto, vemos que el objetivo original del proyecto de probar que la dispersión fue producto de efectos naturales no se cumplió, en tanto que no es de esta naturaleza pero, al analizarlo en cuanto a los factores humanos, se abren nuevas posibilidades.

En lo que se refiere a la población ósea analizada, cabe destacar que las primeras propuestas sobre la minería de cinabrio sugieren: un trabajo eminentemente masculino, ejecutado en régimen de esclavitud, promovido con fines religiosos y con la participación de menores de edad (Langenscheidt 1970); que se trataría de un trabajo eventual (Velasco 1986:22-23) y, finalmente, se reconsidera como una economía especializada, con trabajo especializado de tiempo completo efectuado por varones (Herrera 1994).

Cabe decir que después de analizar los resultados obtenidos, consideramos que la minería fue 
un trabajo especializado que involucró a toda la población, ya que incluye una gran cantidad de labores y cada una significó diversos niveles de exposición al mineral, impactando al organismo en diversas formas. Al tener los resultados de los estudios antropofísicos pudimos constatar que:

1. Como era evidente desde el campo, los problemas dentales eran numerosos afectando a un porcentaje moderado de la población -menos del 50\%-, sin embargo, el nivel de afectación en algunos especímenes aislados fue alto.

2. Existen lesiones causadas por traumatismos en varones y mujeres.

3. La incidencia de enfermedades articulares como osteofitosis, reumatismo, espondilitis anquilosante, afectó a varones y mujeres. $\mathrm{La}$ incidencia no es muy alta (10 casos del total de 57 adultos analizados), de ellos 5 pertenecen a la población analizada para la determinación de metales pesados y, por ello, coinciden con la presencia los metales, sin embargo, vale indicar que de los casos restantes falta hacer análisis de metales pesados.

4. El mejor ejemplo de bioacumulación son los nonatos, ya que ellos nunca se sometieron a labores mineras, no obstante, se exponen a los metales pesados a través de la madre. Su contaminación es orgánica acumulada durante la gestación.

Para este caso en particular estamos realizando un estudio separado, ya que reflejan la condición de salud de la madre y del feto, para así entender el tipo de contaminación materna que tuvo que existir para que naciera contaminado en grados extremos, lo que seguramente fue la causa de la muerte (Español 2001:28).

En el caso de las mujeres, que siempre se pensaron exentas del trabajo de la minería, podemos ver, sin embargo, que en la sierra se observa la cooperación activa que dejó huellas en sus brazos y piernas, por lo que proponemos que debieron tener una participación en las labores de molienda y concentración. Una antigua propuesta era que las labores mineras solamente se realizaban en el patio de las minas, no obstante, el análisis de los sedimentos de los sitios de Ranas y Toluquilla mostró concentraciones que superan los valores de fondo regionales en lugares que tradicionalmente se consideraban espacios sacros, como los cuartos junto al juego de pelota. Por ello, suponemos que posiblemente el trabajo de molienda y envasado se realizaba en la zona arqueológica de Toluquilla, y por esto, afectó también a la población infantil. Por eso concluimos que la minería y la mineralurgia provocaron la afectación a las condiciones de salud de toda la población, quizás producto de la ingesta, particularmente en el caso de los niños, o por el trabajo en los adultos. Por todo ello, es importante analizar la presencia de cada metal en función de la edad y sexo de cada individuo.

Por último, es importante resaltar que al inicio de nuestro trabajo, cuando seleccionamos los individuos para determinar los metales, no contábamos con los resultados de los análisis óseos. Al finalizar, fue evidente que de los nueve adultos estudiados, cinco tienen problemas articulares, que coinciden con problemas de entesopatías (4), y los demás, presentan los problemas anteriores y traumatismos (3), fusión (3) y callos óseos. A partir de lo anterior, podemos observar que la relación entre problemas articulares y de traumatismos óseos está relacionada con la presencia de metales, lo que es un indicador de la actividad relacionada con la minería de cinabrio como actividad económica de la población adulta de Toluquilla en la Sierra Gorda de Querétaro.

Agradecimientos: Manifestamos nuestro agradecimiento al INAH por su apoyo a las investigaciones Arqueológicas y su apertura para la cooperación Interinstitucional de carácter multidisciplinario; al PAPIIT-UNAM (clave IN16806), al CONACYT de México (Proyectos de Cooperación Científica y Tecnológica Internacional bilateral y al NKTH (Hungarian-Mexican Intergovernamental $S \& T$ Cooperation programme) por el apoyo al proyecto multidisciplinario. $\mathrm{Al}$ arqueólogo Mario Pérez Campa $\dagger$ (qepd), Secretario Técnico del INAH, por sus gestiones para la consecución de recursos; al doctor Luis Barba del IIA-UNAM, por sus valiosos comentarios y sugerencias; a los doctores Peter Scharek (MAFI-Hungría) y Gilberto Hernández Silva (Geociencias-UNAM), por integrarnos a su equipo de investigación. Por último, agradecemos a los organizadores del Primer Congreso de Minería Prehispánica, por el evento efectuado y la promoción de su publicación, así como a los evaluadores de la misma. 


\section{Referencias Citadas}

Domínguez-Bella, S. 2010. Aplicaciones de las técnicas experimentales y la mineralogía a la arqueometría. Los pigmentos de cinabrio del dolmen de Alberite I, Villamartín (Cádiz). En Minerales y Rocas en las Sociedades de la Prehistoria, editado por S. Domínguez-Bella; J. Ramos Muñoz, J.M. Gutiérrez López, M. Pérez Rodríguez, pp. 235-244. Universidad de Cádiz, Cádiz.

- - - 2011. Rojo y verde: los minerales en la vida y la muerte del megalitismo neolítico. Ponencia presentada en el IV Encontro arqueolóxico do Barbanza, La Coruña.

Forbes R.J. 1965-1967. Studies in Ancient Technology. Leiden, Alemania.

Hernandez-Silva, G., J. Solorio-Munguia, L. Vassallo-Morales y L. Flores-Delgadillo 2005. Monitoreo de contaminantes en las cuencas de los ríos Guanajuato y Turbio y su impacto en el río Lerma, Guanajuato, México. SIN: 0185-5530, Editorial IGeol. UNAM, Edición 1a., Boletín 112:109-123. México D.F.

Hernández, G. 2009: Mercurio en suelos, sedimentos y terreros al sur de la Sierra Gorda de Querétaro, México. En Mercurio; Impacto en el Hombre y la Naturaleza al sur de la Sierra Gorda de Querétaro, editado por G. Hernández, pp. 41-48. Centro de Geociencias, Campus UNAM-Juriquilla, México.

Herrera, A. 1991. Acerca de un Atlas arqueológico para el Estado de Querétaro. Archivo Técnico INAH, México. Manuscrito en posesión del autor.

- - - 1993. Informe de Rescate de Información arqueológica. Archivo Técnico, INAH, México. Manuscrito en posesión del autor.

- - - 1994. Minería de Cinabrio en la Región de El Doctor, Querétaro. Tesis para optar al grado de Licenciado en Arqueología. ENAH. México.

- - - 2007. Ranas y sus asentamientos cercanos. Ponencia presentada en XXVIII Mesa redonda de la Sociedad Mexicana de Antropología, Ciudad de México.

- - - 2009. Zona Arqueológica Ranas, Miniguía. INAH, México.

Herrera, A. y E. Mejía. 2009. Ranas Toluquilla y el mercurio. En Mercurio; Impacto en el Hombre y la Naturaleza al sur de la Sierra Gorda de Querétaro, editado por G. Hernández, pp. 98107. Centro de Geociencias, Campus UNAM-Juriquilla, México.

Langenscheidt, A. 1970. Minería Prehispánica. En Minería Prehispánica en la Sierra de Querétaro, editado por A. Langenscheidt, pp. 43-57. Secretaría del Patrimonio Nacional, México.

Márquez, L. y P. Hernández 2006. Salud y Sociedad: en el México Prehispánico y Colonial. CONACULTA-INAH. México.

Martín-Gil, J., F.J. Martín-Gil, G. Delibes-de-Castro, P. ZapateroMagdaleno y F.J. Sarabia-Herrero 1994. Neolítico. Uso del Cinabrio. Investigación y Ciencia 219:29-30.
Mejía, E. 1994. Proyecto Toluquilla. Archivo Técnico, INAH, México. Manuscrito en posesión de la autora.

- - 2002. Proyecto Toluquilla informe técnico quinta temporada 2001. Archivo Técnico, INAH, México. Manuscrito en posesión de la autora.

- - - 2003. Proyecto Toluquilla informe técnico sexta temporada 2002. Archivo Técnico, INAH, México. Manuscrito en posesión de la autora.

- - - 2004. Proyecto Toluquilla informe técnico séptima temporada 2002. Archivo Técnico, INAH, México. Manuscrito en posesión de la autora.

- - - 2005. Proyecto Toluquilla informe técnico octava temporada 2004. Archivo Técnico, INAH, México. Manuscrito en posesión de la autora.

- -- 2010. Toluquilla: Ciudad entre Nubes, Ancestros y Ofrendas. Tesis para optar al grado de Doctor en Antropología, ENAH, México.

Minami, T. 2005. Using sulfur isotopes to determine the sources of vermillion in ancient burial mounds in Japan. Geoarchaeology 20:79-84.

Salminen, R., A. Demetriades y S. Reeder 2005. Introduction. En Geochemical Atlas of Europe. Part 1. Background Information, Methodology and Maps, editor R. Salminen. Geological Survey of Finland, Espoo.

Salminen, R. (ed.) 2005. Geochemical Atlas of Europe. Part 1, Background Information, Methodology and Maps.(IUGS/ IAGC Global Geochemical Baselines) Geological Survey of Finland. Espoo, Finland, consulta digital, http://www.gsf.fi/ publ/foregsatlas/article.php?id=5. Enero 2008 .

SEMARNAT 1993. Norma Oficial Mexicana que establece las características de los residuos peligrosos y el listado de los mismos y los límites que hacen a un residuo peligroso por su toxicidad al ambiente. Diario Oficial de la Federación, publicado el 22 de octubre de 1993, entrando en vigor al día siguiente, Código NOM-052-SEMARNAT. 1993, antes NOM-052-ECOL-1993).

Shepherd, R. 1980. Prehistoric Mining and Allied Industries. Academic Press, London.

Velasco, M. 1978. Algunos asentamientos Prehispánicos en la Sierra Gorda. En Problemas del Desarrollo Histórico de Querétaro, editado por M. Velasco, pp. 44-50. SMA, INAHSEP, Querétaro.

Velasco, M. 1986. Zona Arqueológica Ranas. Ideas 1:21-24.

Walters, R.L. 1991. The use of estandar reference materials for quiality assuranc in inductively coupled plasma optical emition and atomic absortion spectrometry. Spectrochim Acta the Bulletin at Spectros 46:1593-1605. 


\section{Notas}

1 En México es común que para soportar objetos pesados se

3 Los resultados del estudio de patrones de puntos con estudios usan sacos o bolsas sostenidos por una banda que se apoya en la frente para sostener el peso con todo el cuerpo.

2 La Norma Mexicana más rigurosa para el mercurio es de 0,2 partes por millón, en el arsénico la norma establece una concentración no mayor a 5 partes por millón, SEMARNAT 1993. Walters 1991:1593-1605. de vecino más cercano muestra que el valor promedio de distancia entre asentamientos fue de $1,2 \mathrm{~km}$, con respecto a las minas ocurre una correlación positiva con un valor $r=0,787 \pm 0,3$, resultando ser significativa a 2 sigma, con un nivel de certidumbre de $83,3 \%$. 